some copper that dissolves gradually in the uterine secretions. ${ }^{15}$ The Dalkon shield (Robins) is said to contain little surface copper available for release, while others such as the Gravigard (Searle), consisting of copper wire round a plastic stem, are specifically designed to release the metal.

Various hypotheses have been advanced to explain the contraceptive action of copper, including endometrial enzyme alterations that are hostile to implantation, changes in cervical mucus, local inflammatory reaction, and possible toxic effects on the embryo. ${ }^{16} \mathrm{~A}$ teratogenic effect from intrauterine copper after implantation cannot be shown in rabbits, hamsters, and rats. ${ }^{17}$ In human adult and fetal tissue cultures the introduction of the Dalkon shield had no noticeable effect on cell growth, although fibroblast changes appeared with rising copper concentrations from the Gravigard and comparable solutions of copper chloride. ${ }^{18}$

The extrapolation to man of the results of teratological experiments in animals is fraught with difficulties. ${ }^{19}$ In the field of reproduction species differences are particularly variable. In human fetal development the limb buds appear in the fourth week and by the eighth all structures including all fingers and toes are clearly recognisable. The critical period for teratogenesis is relatively short compared with the susceptible period in the mouse or rat, in which it is about a third of the length of gestation. ${ }^{20}$ Before implantation all surviving cells have the potential of forming a complete embryo. During this phase, which extends to six and a half days in mice, eight days in rats, and 12 to 13 days in man, it is difficult if not impossible to induce malformations.

Despite the reassuring experimental work on rodents and human tissue cultures it is unrealistic on the available evidence to dismiss the possibility of a teratogenic effect from a retained intrauterine device. Serious consideration should be given to terminating early pregnancies with a retained intrauterine device. A careful search, including a placental and pelvic radiograph, should be made for intrauterine devices in women who may have used them in the past and who give birth to malformed infants. More information is urgently needed on the outcome of pregnancies complicated by the presence of intrauterine contraceptive devices.

I thank Mr W Warr of the Fulmer Research institute for performing emission spectrographic analysis on the devices. The first patient is now under the care of $\mathrm{Mr}$ Brian Andrews and the second under the care of Mr John Strachan.

\section{References}

${ }^{1}$ Frantz, C H, and O'Rahilly, R, fournal of Bone and foint Surgery, 1961, 43A, 1202.

2 Farmer, A W, and Laurin, C A, fournal of Bone and foint Surgery, $1960,42 \mathrm{~A}, 1$.

${ }^{3}$ Kruger, L M, and Talbott, R D, fournal of Bone and foint Surgery, 1961, 43A, 625.

4 Wilson, J M, Teratology, 1973, 7, 3.

${ }^{5}$ Miller, J W, Lancet, 1962, 2, 599 .

${ }^{6}$ Vessey, M P, et al, Lancet, 1974, 1, 495.

7 Allen, J R, Obstetrics and Gynecology, 1972, 40, 225.

8 Mishell, D R, and Moyer, D L, Clinical Obstetrics and Gynecology, 1969, $12,179$.

'Misenheimer, H R, and Garcia-Bunuel, R, Obstetrics and Gynecology, $1969,34,368$.

10 McCracken, J S, British Medical fournal, 1975, 2, 684

11 Tischler, E, Medical fournal of Australia, 1970, 1, 441.

${ }^{12}$ Steven, J D, and Fraser, I S, Fournal of Obstetrics and Gynaecology of the British Commonwealth, 1974, 81, 282.

${ }^{13}$ Wiles, P J, and Zeiderman, A M, Obstetrics and Gynecology, 174, 44, 484.

14 Telson, M M, and Forfar, J O, Developmental Medicine and Child Neurology, $1969,11,3$.

${ }^{15}$ Zipper, J A, Tatum, J, and Pastere, L, American fournal of Obstetrics and Gynecology, 1969, 105, 1274.

${ }_{16}$ British Medical fournal, 1974, 2, 181.

${ }_{17}$ Chang, C C, and Tatum, H J, Contraception, 1973, 7, 413.

18 Jones, R W, Gregson, N M, and Elstein, M, British Medical fournal, 1973, 1,520 .

19 Warkany, J, Congenital Malformations, Chicago, p 101. Year Book Medical Publishers, 1971.

20 Brent, R L, Pediatrics, 1974, 53, 821.

\title{
Extrinsic allergic alveolitis in Scottish maltworkers
}

\author{
I W B GRANT, E S BLACKADDER， M GREENBERG， W BLYTH
}

British Medical fournal, 1976, 1, 490-493

\section{Summary}

In a survey of respiratory disease in the Scottish malting industry $5 \cdot 2 \%$ of employees were found to have symptoms of extrinsic allergic alveolitis. In most cases the disease was mild and not associated with any serious respiratory disability. It was significantly less common where modern mechanical methods of malting were used. Mycological and serological studies suggested that

Respiratory Unit, Northern General Hospital, Edinburgh EH5 2DQ

I W B GRANT, MB, FRCP, consultant physician

Health and Safety Executive, Employment Medical Advisory Service

E S BLACKADDER, MFCM, DIH, senior employment medical adviser (Scotland)

M GREENBERG, MB, MRCP, senior employment medical adviser

Department of Botany, University of Edinburgh

W BLYTH, BSC, PHD, lecturer it was usually caused by a type 3 allergic reaction to Aspergillus clavatus.

\section{Introduction}

It has been known since the beginning of the century that there is much chronic respiratory ill health among men employed in the malting industry. ${ }^{1}$ The first indication that this might be due, at least in part, to a specific respiratory disease peculiar to maltworkers came in a report from France published nearly 50 years ago. ${ }^{2}$ Although its authors originally suspected that the pulmonary changes were due to some kind of allergic reaction to Aspergillus fumigatus, they eventually discarded this theory because of the absence of eosinophils in the sputum and concluded that the illness was due to a systemic and toxic effect of aspergillus and mucor. The possibility of an allergic basis for some forms of respiratory disease in maltworkers then seems to have been forgotten until seven years ago, when Riddle et $a l^{3}$ and Channell $e t a l^{4}$ reported four severe cases of extrinsic allergic alveolitis occuring in open-floor maltings and apparently caused by a type 3 allergic reaction to $A$ clavatus. The diagnosis in these four cases was supported by clinical, radiographic, mycological, and serological evidence and by provocation test results. 
After the discovery of these cases concern was expressed that the disease might represent an important health hazard in the malting industry, and it was therefore decided to investigate the prevalence of extrinsic allergic alveolitis among Scottish maltworkers. The survey was carried out in 1972 by doctors and statisticians from the Employment Medical Advisory Service, respiratory physicians from National Health Service hospitals in Scotland, and a mycologist from the Department of Botany at Edinburgh University.

\section{Design of survey}

We decided to aim at a $100 \%$ sample of the Scottish malting industry and its employees because of the relatively small numbers of men at risk and the variety of malting processes within the industry and because the maltings were widely separated geographically. A team of doctors visited every maltings in Scotland and completed for every employee who was willing to co-operate the MRC questionnaire on respiratory symptoms, ${ }^{5}$ supplemented by standardised questions on the time relationship of dust exposure to the appearance and remission of respiratory and other symptoms. A full occupational history was obtained from every man, and the type of malting process in which he had been engaged during the previous three years was recorded. The following investigations were also carried out: chest $x$-ray examination; measurements of forced expiratory volume in one second $\left(\mathrm{FEV}_{1}\right)$ and forced vital capacity (FVC); skin sensitivity (prick) tests to detect an immediate reaction to $(a)$ common allergens (grass pollen and Dermatophagoides pteronyssinus) and (b) a group of allergens (occupational allergens) prepared from fungi and actinomycetes that had been isolated from the maltings where the earlier cases of extrinsic allergic alveolitis had occurred ; mycological examination of sputum, when available, and also of environmental samples of grain, culms, and dust taken from all maltings included in the survey; and examination of serum for antibodies against occupational allergens, including $A$ clavatus.

The questionnaires and chest radiographs were scrutinised by members of the project team, and all men who had had symptoms suggestive of extrinsic allergic alveolitis in the previous three years or whose chest radiographs were reported to show diffuse pulmonary shadowing were recalled for further investigation by one of the respiratory physicians. In addition, those men in whom a significant abnormality, apparently unrelated to their occupation, was reported on chest radiographs were referred through their general practitioners to a local chest clinic.

\section{MALTING}

Malt is barley that has been moistened, allowed to germinate, and then dried. The object of the process is to allow proteolytic and diastatic enzymes to reduce proteins and starch to sugars and other diffusible substances. The traditional method of promoting germination is to spread the moistened barley in a thick layer on a concrete floor (open-floor malting). Germinating barley is liable to be contaminated by fungi, including $A$ clavatus, and workers handling it may inhale many fungal spores. In the more modern maltings the process is partially or completely mechanised, and the dust hazard is correspondingly reduced. In the "Saladin" process it has not been eliminated, since exposure to fungal spores occurs when the malt is being screened and milled and when maintenance work is being carried out on the plant. The "drum" method of malting is an entirely closed process, from which there is virtually no dust hazard.

\section{SURVEY POPULATION}

Of the nominal roll of 768 workers employed in 56 maltings at the time of the survey $711(92 \cdot 6 \%)$ were included in the field study. The remaining 57 men were either off sick (10), on holiday (15), on the night shift (6), or off work for unknown reasons (12) or they refused to take part (14).

One-hundred-and-twenty-seven $(18 \%)$ of these 711 men were recalled for further investigation by a respiratory physician because they had symptoms suggestive of allergic alveolitis (116 men (91\%)) or radiographic changes suggestive of allergic alveolitis (11 men $(9 \%))$. At this investigation a detailed occupational history was taken to identify specific dust hazards and evaluate their importance in relation to frequency and intensity of exposure; and the time relationship of symptoms to dust exposure was critically assessed. A full clinical examination was carried out, the chest radiograph was repeated, and $\mathrm{FEV}_{1}$ and FVC were measured again, since the original measurements had been made about three months earlier. In 38 of the 63 maltworkers examined at the Northern General Hospital, Edinburgh, the carbon monoxide transfer factor (TCO) was measured. Any other respiratory abnormality was recorded.

Diagnostic index-The severity of extrinsic allergic alveolitis was assessed in each maltworker by grading his symptoms and their time relation to dust exposure from 0 to 4 . A worker scored 4 if he had cough, chest tightness, and dyspnoea, with or without fever, that occurred regularly some hours after exposure to dust and his symptoms disappeared during periods of absence from work. He scored 3 if he regularly developed a cough, but no other symptoms, in similar circumstances. He scored $2 a$ if he had a cough that occurred occasionally some hours after exposure to dust and $2 b$ if he had a preexisting cough with or without dyspnoea (possibly due to chronic bronchitis) that became worse some hours after exposure to dust. He scored one if he had the same symptoms as for 2 but the time relation between symptoms and exposure was uncertain or inconstant. He scored 0 if he had no symptoms or ones that were clearly due to another form of respiratory disease.

\section{Results}

\section{PREVALENCE OF EXTRINSIC ALLERGIC ALVEOLITIS}

Scores on the diagnostic index of 3 or 4 indicated that the diagnosis was probable or certain, whereas a score of 0 indicated that extrinsic allergic alveolitis had been excluded; scores of 1 or 2 indicated that it was unlikely or possible. Thirty-seven of the 127 maltworkers suspected of having extrinsic allergic alveolitis had scores of 3 or 4, and on this basis the prevalence of the disease among the 711 Scottish maltworkers who completed questionnaires was $5 \cdot 2 \%$ (table I).

TABLE I-Prevalence of extrinsic allergic alveolitis in Scottish maltworkers

\begin{tabular}{l|c|c|c|c}
\hline Malting process: & Open floor & Saladin & $\begin{array}{c}\text { Modern } \\
\text { mechanical }\end{array}$ & $\begin{array}{c}\text { All } \\
\text { processes }\end{array}$ \\
\hline $\begin{array}{l}\text { No of workers } \ldots \text { w } \\
\text { No } \text { (\%) scoring } 3 \text { or } 4 \text { on } \\
\text { diagnostic index } \ldots\end{array}$ & 339 & 195 & 177 & 711 \\
\hline
\end{tabular}

The disease was most prevalent in open-floor maltings $(6.8 \%)$ and Saladin maltings $(6 \cdot 2 \%)$ and least prevalent in drum maltings $(1 \cdot 1 \%)$ Geographically it was most prevalent in the East Lothian and Edinburgh areas $(9.7 \%)$, and there were no cases in the Glasgow and Airdrie areas, where modern mechanical malting processes were much more extensively used. Although most of the distilleries in the Highlands and Islands had open-floor maltings the prevalence there was relatively low $(4 \cdot 2 \%)$.

\section{CLINICAL AND RADIOGRAPHIC FINDINGS}

In none of the maltworkers, even those with a diagnostic score of 3 or 4, were physical signs of allergic alveolitis detected, nor was micronodular shadowing observed on any of the chest radiographs. Although a radiological abnormality suggestive of extrinsic allergic alveolitis had been reported on the films of 11 maltworkers taken during the field study, these findings were not confirmed when radiographic examination was repeated. Possibly the technical characteristics of the radiographs obtained in the field study were different, and the observers who read the initial radiographs may have over-reported "micronodular shadowing" because they were aware that this abnormality occurred in maltworkers.

\section{RESPIRATORY FUNCTION TESTS}

Respiratory function tests in the 37 men with alveolitis showed a restrictive ventilatory defect, usually mild, in six men and an obstruc- 
tive defect in eight men, four of whom also had symptoms of chronic bronchitis. In the remaining 23 men the $\mathrm{FEV}_{1}$ and FVC were normal Among the 38 men in whom it was measured the Tco was usually reduced in maltworkers with chronic bronchitis. When these men were excluded, however, a subnormal Tco was recorded in six out of 13 men with diagnostic scores of 3 or 4 . In contrast, none of the 13 men with scores of 0,1 , or 2 had a subnormal Tco.

\section{SKIN SENSITIVITY TESTS}

Of the 711 maltworkers $207(29 \%)$ had a positive immediate prick test reaction (wheal of at least $3 \mathrm{~mm}$ in diameter) to grass pollens or $D$ pteronyssinus, or both, and were classified as "atopic." Ten of the men with positive reactions were among the 37 with a certain or probable diagnosis of extrinsic allergic alveolitis. The difference between the proportions of atopic maltworkers with and without extrinsic allergic alveolitis was not statistically significant.

Immediate prick test reactions for occupational allergens were recorded in $9 \%$ of all maltworkers but in $24 \%$ of those with extrinsic allergic alveolitis $(\mathrm{P}<0.05)$. Of the 207 atopic workers $4.3 \%$ had immediate prick test reactions to one or more occupational allergens compared with $10.7 \%$ of 504 non-atopic workers. The negative correlation between positivity to occupational allergens and positivity to common allergens was statistically significant $(P<0.01)$.

\section{MYCOLOGICAL AND SEROLOGICAL STUDIES}

Twelve maltings showed some degree of contamination with $A$ clavatus, six of them from a single source, such as intake grain, dust, or culms. Three maltings showed two or three sources, and three had four sources from which the fungus was isolated. In a further four maltings, although the maltings themselves yielded no cultural evidence of contamination, some maltworkers had $A$ clavatus in their sputum. Altogether 250 men were employed in these 16 maltings. Table II shows that a positive precipitin test reaction for $A$ clavatus (mycelial antigens) was recorded more than twice as often, and the prevalence of extrinsic allergic alveolitis was almost twice as high, in those 250 men than in the 461 men employed in the 40 maltings where $A$ clavatus was not isolated on environmental sampling or sputum examination. The number of workers with a positive precipitin test result was four times the number with extrinsic allergic alveolitis.

TABLE II-Prevalence of extrinsic allergic alveolitis and positive serological results in relation to isolation of A clavatus from environment or sputum, or both

\begin{tabular}{|c|c|c|c|}
\hline & \multicolumn{2}{|c|}{$A$ clavatus } & \multirow{2}{*}{ Total } \\
\hline & Present & Absent & \\
\hline $\begin{array}{l}\text { No of workers } \ldots \\
\text { No }(\%) \text { with positive precipitin test } \\
\text { results } \\
\text { No }(\%) \text { with extrinsic allergic alveolitis }\end{array}$ & $\begin{array}{c}250 \\
76(30) \\
19(7 \cdot 6)\end{array}$ & $\begin{array}{l}461 \\
66(14) \\
18(3.9)\end{array}$ & $\begin{array}{c}711 \\
142(20) \\
37(5 \cdot 2)\end{array}$ \\
\hline
\end{tabular}

A positive serological test for mycelial antigens of $A$ clavatus was recorded in $142(20 \%)$ of the 711 maltworkers. There was an obvious positive correlation between the diagnosis of extrinsic allergic alveolitis and the rate of seropositivity, which ranged from $11 \%$ in asymptomatic maltworkers to $82 \%$ in those with a diagnostic score of four (table III).

TABLE III-Results of A clavatus precipitin tests in relation to clinical diagnosis of extrinsic allergic alveolitis

\begin{tabular}{l|c|c|c|c|c|c}
\hline & $\begin{array}{c}\text { No } \\
\text { clinical } \\
\text { assessment }\end{array}$ & \multicolumn{5}{|c}{ EAA Diagnostic grade } \\
\cline { 5 - 7 } & 584 & 74 & 3 & 13 & 15 & 22 \\
\hline $\begin{array}{c}\text { Total population } \\
\begin{array}{c}\text { No (\%) with positive } \\
\text { result } \ldots\end{array}\end{array}$ & $69(12)$ & $13(18)$ & $1(33)$ & $7(53)$ & $9(60)$ & $18(82)$ \\
\hline
\end{tabular}

There was no clear relation between sputum and environmental mycological findings and seropositivity to other fungi, such as $A$ fumigatus, $A$ niger, Rhizopus sp, and Cladosporium sp. A further indication that mycelial antigens of $A$ clavatus were of aetiological importance was that they showed very few cross-reactions with other fungal species or genera.

The results of the mycological and serological studies will be reported in detail elsewhere.

\section{Discussion}

The typical features of a severe case of extrinsic allergic alveolitis include numerous coarse crepitations on auscultation, diffuse micronodular shadowing throughout both lungs on $x$-ray examination, physiological evidence of restrictive lung disease and a gas transfer defect, the presence of specific serum antibodies against the suspected antigen, and a positive provocation test result. Nevertheless, many maltworkers with a history of typical symptoms of extrinsic allergic alveolitis show no abnormal physical signs, no radiographic abnormality, and no demonstrable impairment of pulmonary function. We assumed for the purpose of this survey, since no other explanation seems tenable, that such men are suffering from a milder form of the disease or are in a clinical remission. Hence we relied primarily on environmental and symptomatic criteria for diagnosing extrinsic allergic alveolitis and estimated the prevalence of the disease on that basis.

Although the prevalence of extrinsic allergic alveolitis among Scottish maltworkers was $5 \cdot 2 \%$, most cases were mild, possibly because men with more severe disease had already left the industry. None of them had significant radiographic abnormalities, but a gas transfer defect was recorded in six of the 13 maltworkers with extrinsic allergic alveolitis (but without chronic bronchitis) in whom the Tco was measured.

The much lower prevalence of the disease in maltings where modern mechanical processes were in operation $(1.1 \%)$ than in open-floor $(6.8 \%)$ and Saladin $(6.2 \%)$ maltings suggests that replacement of the older methods by the new mechanical processes might substantially reduce, and perhaps eventually eliminate, this form of extrinsic allergic alveolitis. It is claimed, however, that open floor malting contributes to the characteristic flavour of high quality malt whisky and it is unlikely that those Highland distilleries which specialise in the production of "single malt" whiskies will ever abandon their traditional practices. In fact, the prevalence of extrinsic allergic alveolitis in these distilleries was relatively low (just over $4 \%$ ), although many still have open-floor maltings. The probable reason for this is that they use only locally harvested high-quality barley, which is less liable to fungal contamination than the inferior imported, and often damaged, grain used in some open-floor maltings, particularly in breweries.

This survey has provided much evidence to support the view that a type 3 allergic reaction to $A$ clavatus is responsible for many cases of extrinsic allergic alveolitis in maltworkers. Antibodies against $A$ clavatus mycelial antigens were recorded more than twice as often, and the prevalence of extrinsic alveolitis was almost twice as high, when there was mycological evidence of environmental contamination by this fungus than when there was not. Furthermore, there was an obvious correlation between the clinical diagnosis and seropositivity, which rose from $11 \%$ in asymptomatic maltworkers to $82 \%$ in those with a certain diagnosis of extrinsic allergic alveolitis. There was nothing in the serological findings to implicate actinomycetes or fungi other than $A$ clavatus in the production of extrinsic allergic alveolitis in maltworkers.

In the field study it was possible to undertake skin (prick) tests only for immediate hypersensitivity reactions. These showed that (a) the proportion of atopic subjects among maltworkers with extrinsic allergic alveolitis was the same as among asymptomatic maltworkers, (b) there was a significantly higher rate of positive test results with "occupational" (mainly fungal) 
allergens in maltworkers with extrinsic allergic alveolitis than in the rest of the maltworker population, and $(c)$ atopic maltworkers had a significantly lower rate of skin sensitivity to occupational allergens than non-atopic workers. The first observation is not surprising, since extrinsic allergic alveolitis is not due to a type 1 allergic reaction. The second is of interest, since it suggests that the type 3 allergic reaction responsible for the disease may be accompanied by a type 1 reaction to the same allergen. The third is difficult to explain except, perhaps, on the rather dubious hypothesis that skin sensitivity to common allergens in some way inhabits the development of skin sensitivity to occupational allergens. It would appear, however, that this phenomenon does not protect such patients from the type 3 antigen-antibody reaction believed to be responsible for extrinsic allergic alveolitis.

With increasing mechanisation of the malting process the prevalence of this disease is likely to diminish rapidly, and there may never be another opportunity to confirm or refute the hypothesis that in most cases extrinsic allergic alveolitis is a pulmonary allergic reaction to inhaled spores of $A$ clavatus.
We thank Dr Robert Whitelaw and Dr J Douglas Bell of the Employment Medical Advisory Service for their help in the field survey; Drs B R Hillis, R N Johnston, A P Littlewood, R S McNeil, W D Murray, and B H R Stack for making many of the clinical assessments; and Miss Jane Williamson for typing the manuscript. We also wish to acknowledge the valuable help we received from the Scottish malting industry and the willing and cheerful co-operation we obtained from the maltworkers.

This study was supported by a grant from the Secretary of State's medical research fund.

\section{References \\ 1 Home Office, Report of the Departmental Committee on Compensation for Industrial Diseases, Cmnd 3496. London, HMSO, 1907. \\ 2 Vallery-Radot, L P, and Giroud, P, Bulletins et Mémoires de la Société Médicale des Hôpitaux de Paris, 1928, 52, 1632. \\ ${ }^{3}$ Riddle, H F V, et al, Thorax, 1968, 23, 271. \\ 4 Channell, S, et al, Quarterly fournal of Medicine, 1969, 38, 351. \\ 5 Medical Research Council Committee on Research into Chronic Bron- chitis, Instructions for the Use of the Questionnaire on Respiratory Symptoms. p 16. London, MRC, 1966.}

\section{Summary}

Controlled trials of $0.5 \%$ silver nitrate compresses (SN), $1 \%$ silver sulphadiazine cream (SSD), and a cream containing $0.5 \%$ silver nitrate and $0.2 \%$ chlorhexidine digluconate (SNC) showed that all were comparably effective in protecting burns from infection. SN compresses were much less active against miscellaneous Gram-negative bacilli than the other preparations, and the mean morning and evening temperature and respiration rates in the patients treated with SN compresses were higher than those of patients treated with SSD. Pseudomonas aeruginosa and Proteus spp, though rare in all groups, were less often found in the patients treated with SN compresses. Sulphonamide-resistant Gram-negative bacilli became predominant during the trial of SSD cream on extensive burns and the prophylactic effectiveness of that preparation was thus reduced in the later stages of the trial.

\section{Introduction}

Earlier controlled trials in this unit have shown the effectiveness of various forms of topical chemoprophylaxis against bacteria

\footnotetext{
MRC Industrial Injuries and Burns Unit, Birmingham Accident Hospital, Birmingham B15 1NA

E J L LOWBURY, DM, FRCPATH, bacteriologist and honorary director of hospital infection research laboratory

J R BABB, FIMLT, senior research officer

K BRIDGES, BSC, bacteriologist

D M JACKSON, MD, FRCS, consultant surgeon
}

that commonly colonise burn wounds and occasionally cause invasive infection. ${ }^{1-3}$ Apart from polymyxin, antibiotics have proved unsuitable, even when effective, for routine prophylaxis, mainly because their use encourages the emergence of resistant variants of organisms that are usually sensitive; it is obviously important to reserve such agents as gentamicin for therapeutic use in severe established sepsis.

With the introduction of silver nitrate (SN), mafenide, ${ }^{5}$ and silver sulphadiazine (SSD), ${ }^{6}$ topical chemoprophylaxis has been more widely used and received further support from controlled trials. ${ }^{7-9}$ We report here the results of two trials, one comparing the prophylactic effects of SSD and SN on severe burns, and one comparing the prophylactic effects of SSD and silver nitrate chlorhexidine (SNC) on both extensive and less severe burns.

\section{Silver sulphadiazine compared with silver nitrate} METHODS

Patients with extensive burns were allocated on admission alternately to a control group in which treatment was with compresses of $0.5 \% \mathrm{SN}$ - the best established method for treating extensive burns in our previous experience 7810 - and to a group treated with $1 \%$ SSD cream (Flamazine), which has been shown ${ }^{9}$ to be effective prophylaxis for less extensive burns. Patients were eligible for the trial if they had a mortality expectation of $0 \cdot 1$ or more (calculated from their age and area of burn on Bull's ${ }^{11}$ table of expected mortality). Patients with burns usually treated by the exposure method-those of the face and some burns of the trunk-were excluded from the trial. Children under 3 years of age were excluded because of the special danger in them of electrolyte imbalance caused by treatment with hypotonic silver nitrate solution. Dressings were applied and serum electrolytes controlled as described. ${ }^{7}$

Patients treated with SSD cream had their burns dressed as soon as possible after admission, the cream being applied thickly on strips of sterile gauze, which were covered with cotton wool and held in 